\title{
A voz feminina na narrativa infantil da angolana Maria Celestina Fernandes ${ }^{1}$
}

\author{
The female voice in the children's narrative of the Angolan \\ writer Maria Celestina Fernandes
}

Marcio Jean Fialho de Sousa *

Universidade de São Paulo,

São Paulo, São Paulo, Brasil

Resumo: O objetivo deste artigo é analisar como a contribuição da escritora angolana, Maria Celestina Fernandes, no rol das obras das Literaturas Africanas de Língua Portuguesa, apresenta aspectos inovadores e significativos para a formação do leitor infantil. Além disso, demonstrar como os valores das culturas tradicionais são constantemente atualizados como forma de perpetuação das culturas africanas, simbolicamente demonstrada pela figura do "velho" e pela contação de história.

Palavras-chave: Tradição; Leitor infantil; Velho; Angola; Jovem.

Abstract: The aim of this article is to analyze how the contribution of Maria Celestina Fernandes, Angolan writer, among the works of African Literatures of Portuguese Language, presents innovative and significant aspects for the formation of the child reader, and as the values of traditional cultures are constantly updated as form of perpetuation of African cultures, symbolically shown in the figure of the "old" and of storytelling.

Keywords: Tradition; Child reader; Old; Angola; Young.

\section{PERPETUAÇÃO DA TRADIÇÃO NO IMAGINÁRIO COLETIVO COMO ESTRATÉGIA DE RESISTÊNCIA CULTURAL}

Tendo perdido tanto, é positivo pensar que pudemos salvar a consciência de uma História atravessada por tantas derrotas (CHAVES, 1999, p. 18).

Em Angola, mesmo depois de sua independência, em 11 de novembro de 1975, a população sofreu muito, e durante anos, para que a paz tão sonhada pudesse dar sinais de sua existência. Isso porque, quando Portugal anunciou, em 1974, que se retiraria de suas colônias, haja vista não ter mais condições político-econômicas para manter seu sistema colonialista, a União Nacional para a Independência Total de Angola - UNITA

\footnotetext{
${ }^{1}$ Parte deste estudo foi apresentado em forma de comunicação oral no III Encontro com as Literaturas Africanas: Vozes Femininas nas Literaturas Africanas Infantil de Lingua Portuguesa, em março de 2016, em São Paulo.

* Doutor em Letras pela FFLCH-USP, pesquisador do Grupo Eça-USP e do Grupo de Pesquisa Formação Contínua de Professores da PUC-SP. Professor da SEE-SP e da FATEC Sebrae. E-mail:pavlovfialho@usp.br.
} 
se juntou à Frente Nacional de Libertação de Angola - FNLA no conflito armado que irrompe contra o Movimento Popular de Libertação de Angola - MPLA, que liderava a luta pela libertação do país e assume o poder, imediatamente, em 1974/75, durante o processo de descolonização, passando de movimento popular a partido político. Esses conflitos ideológicos seriam responsáveis, logo após a independência, pela guerra civil que tomou o país naquele período, perdurando até o ano de 2002.

É nesse contexto de hostilidade e de consequente miséria que três grandes desafios passaram a ser travados pelos povos angolanos. De um lado a necessidade de erguer o país como uma nação verdadeiramente independente, de outro a luta do povo pela sobrevivência diante da miséria que assolava Angola e, além disso, a necessidade de reconstruir uma identidade nacional que havia sido abafada e quase que aniquilada durante os séculos de colonização. A esse respeito, afirma Rita Chaves, no texto de introdução do livro $A$ formação do romance angolano:

Tendo perdido tanto, é positivo perceber que pudemos salvar a consciência de uma História atravessada por tantas derrotas. Alvos da invasão, fomos privados da empolgada e fugidia convicção dos "barões assinalados" que atingiram "muito mais do que prometia a força humana", para lembrar os belíssimos versos de Camões (CHAVES, 1999, p. 18).

Desse modo, esse passado recente da história de Angola, indubitavelmente, deixa suas marcas na história da literatura nacional, que acaba se tornando um autêntico instrumento de exercício da memória e arcabouço cultural das tradições de outrora e do novo tempo, tal como pode ser lida na obra Mayombe, de Pepetela, publicado em 1980, por exemplo. Essa dialogicidade entre passado e presente, porém, não se dá de modos estanques e díspares, convive mutuamente se complementando e criando novos significados.

A tradição apresentada nas narrativas literárias, de modo geral, aparece como mitos e crenças muitas vezes matizadas por acervos religiosos, históricos e imaginários transmitidos oralmente, ratificando, desta feita, o estabelecimento e a perpetuação de certas tradições.

Esta perpetuação da tradição, sua presentificaç̧ $\square$ o e/ou cristalização no imaginário coletivo, encontra, pois, veículo poderoso nos textos literários como estratégias de resistência cultural, asseverando a estreita relação entre história e literatura. De fato, segundo José Nicolau Gregorin Filho,

$\mathrm{Na}$ construção da identidade cultural de um povo, a literatura ocupa lugar de destaque, pois oferece os universos de relações produzidas na história, ou seja, desde os espaços ocupados e de que maneira esses espaços se ocuparam até as transformações nas relações sociais e os símbolos produzidos na e por essa sociedade. (GREGORIN FILHO, p. 51, 2012)

Ou seja, com a literatura, os aspectos culturais são relatados como um todo, pois não apenas os aspectos concretos e visíveis da história são apresentados, mas também, e de modo bastante singular, a riqueza simbólica que envolve as relações sociais dentro de cada sociedade específica. 
Dessa forma, parafraseando as palavras de Jacques Le Goff (2005), esse exercício de escrita, na busca de resgatar os valores da tradição, procura salvar o passado para servir ao presente e ao futuro, sendo assim "Devemos trabalhar de forma que a memória coletiva sirva para a libertação e não para a servidão dos homens" (LE GOFF, 2003, p. 471).

Nesses termos, faz-se mister a figura da infância, pois, segundo Le Goff (2005), tanto "na história das civilizações, como na dos indivíduos, a infância é decisiva. E muito, senão tudo, ali se decide" (LE GOFF, 2005, p. 107). É nesse período de "infância" que se organizam os modos de pensar e de sentir, responsáveis por formar as mentalidades e as sensibilidades futuras. Conforme José Nicolau Gregorin Filho, "Pensar nas crianças e na sua relação com os livros de literatura é pensar no futuro, e pensar no futuro é ter a responsabilidade de construir um mundo com menos espaço para a opressão das diferenças" (GREGORIN FILHO, 2012, p. 6-7).

É nesse contexto, e com um olhar crítico e apurado, que está inserida Maria Celestina Fernandes, escritora angolana de livros infantis. Fernandes apresenta suas narrativas convidando seu leitor a mergulhar nas histórias vindas da tradição oral popular, transferindo a elas o viés atual da modernidade que, por ter sido subjugada pela cultura eurocêntrica, acaba isolando valores preservados nas culturas locais dos países africanos de língua portuguesa.

A escrita pensada no futuro de uma nação, como sendo espaço de construção de um mundo menos opressivo e em busca de uma identidade de uma nação independente, aparece na obra de Maria Celestina Fernandes a partir do resgate da valorização do saber do indivíduo mais velho, assim como de sua figura representativa.

\section{KALIMBA E A BORBOLETA COR DE OURO: A TRADIÇÃO FACE AOS ASPECTOS CONTEMPORÂNEOS DA NARRATIVA INFANTIL}

Em um contexto de colonização, os colonizados são levados a crer que sua cultura é inferior e, por isso, precisam aprender com os colonizadores, visto que esses são os supostos superiores. Segundo Fanon, todos os esforços são feitos para que o colonizado confesse sua inferioridade cultural (FANON, 2010, p. 271). Por outro lado, com certa atitude de resistência, as culturas locais são ainda vivenciadas nas comunidades autóctones. As tradições orais são retransmitidas às novas gerações, porém há aqueles que, imbuídos de um poder simbólico de representação "se lança freneticamente na aquisição obsessiva da cultura do ocupante, tomando o cuidado de caracterizar pejorativamente a sua cultura nacional” (FANON, 2010, p. 272).

Neste espaço simbólico, é comum na cultura africana, o ancião como responsável por ser, muitas vezes, o portador dos valores transmitidos pela tradição, marca que também é apresentada no livro Kalimba (2015) e nos contos do livro $A$ borboleta cor de ouro (1990), de caráter infantil, mas não apenas destinado às crianças, ambos escritos por Maria Celestina Fernandes.

Os valores resgatados em Kalimba são apresentados pela história de um menino angolano, chamado Kababo, e seu pássaro cujo nome intitula o livro. A narrativa resgata 
um conto cujo enredo retrata um grande período de seca na província de Moxico. Como as reservas alimentícias já estavam se acabando, as pessoas começaram a ficar preocupadas, pois não sabiam o que fazer, caso não viesse a tão esperada chuva:

Esvaziados todos os celeiros, pouco ou nada mais restava para enganar os estômagos. Em todas as cubatas ouvia-se o choro das crianças famintas, os adultos lamentavam-se e não viam forma de sair daquela situação aflitiva.

Porém, alguém dentre a população teve uma ideia luminosa e deu-se a conhecer aos irmãos da sanzala. Reunindo-os todos no jango [...] (FERNANDES, 2015, p. 10-11).

A ideia constituía em que os rapazes fossem a outras zonas a fim de trocarem pertences por alimentos. Todos aceitaram a sugestão e saíram em busca de fazer suas trocas. Ocorre que depois de percorrerem léguas e léguas, encontraram um "velho camponês sentado na berma da estrada" e tinha nas mãos um lindo pássaro. Vendo aqueles rapazes, o kota propõe uma troca na qual ele daria o pássaro e alguém o daria um de seus pertences. Teria sido unânime a recusa à proposta, afinal, também como mecanismo de dominação, ou seja, mediante à fome, à miséria, o colonizado tende a resistir menos, confiar menos em suas próprias lutas. Kababo, por outro lado, depois de esperar seus companheiros seguir caminho, aceitou a troca.

A atitude de Kababo provoca ira entre seus convivas: "os companheiros já não queriam saber do Kababo. Assim ele teve de segui-los guardando distância" (FERNANDES, 2015, p. 17). Porém o que seus companheiros não sabiam é que o pássaro tinha poderes misteriosos, capazes de oferecer ao seu dono tudo o que ele solicitasse, mas Kababo, aconselhado pelo velho senhor, não podia contar o mistério que envolvia a ave, devendo contar apenas depois que retornassem à aldeia e depois de ter oferecido tudo o que a comunidade precisava para sobreviver. Depois que Kababo revela todo o mistério que envolvia o pássaro, a comunidade o proclamaram soba, o rei da aldeia "e toda a gente passou a viver sem dificuldade" (FERNANDES, 2015, p. 26).

A narrativa dessa história pertence estruturalmente ao gênero de tradição oral, grande riqueza local, que pode ser depreendido já no primeiro parágrafo do livro que diz:

A história que vou contar aconteceu há tantos, tantos anos atrás que ninguém, nem mesmo o seculo mais velhinho lá do leste de Angola, ali onde ela nasceu, tem conhecimento da época em que as coisas se passaram (FERNANDES, 2015, p. 6, grifo meu).

Como se vê, a história se apresenta com característica da contação de história, muito presente nas diversas culturas africanas e que, de certa forma, só não foi aniquilada da cultura local por força de resistência, visto que no contexto de colonização, a cultura dos povos dominados é condenada à clandestinidade, sendo que o colonizador tende a olhar esse amor que os colonizados têm às tradições "como uma recusa a submeter-se" à cultura dita "superior"2. Além disso, o contrato fiduciário com o

\footnotetext{
2 Maria Celestina Fernandes mantém em seu texto a fórmula "A história que vou contar aconteceu há tantos, tantos anos atrás", indeterminando o tempo e o espaço dos acontecimentos. Frantz Fanon, discutindo sobre as
} 
leitor é estabelecido a partir do pressuposto de que a tradição e os valores transmitidos pela experiência se sobrepõe a qualquer argumento pessoal. Desse modo, nem mesmo a figura do seculo (velho), aquele que é o detentor do conhecimento por questões etárias, é capaz de questionar.

A tradição acerca das histórias orais é apresentada por Manuel Rui em relação à chegada dos portugueses às terras africanas:

Quando chegaste, mais velhos contavam estórias. Tudo estava no seu lugar. A água. O som. A luz. Na nossa harmonia. [...] É certo que podias ter pedido para ouvir e ver as estórias que os mais velhos contavam quando chegaste! Mas não! Preferistes disparar os canhões (RUI Apud CHAVES, 1999, p. 19).

O que Manuel Rui apresenta nesse fragmento, é a violência que a cultura local teve que ser submetida mediante a chegada dos colonizadores, enquanto naquele momento a cultura africana local oferecia as estórias, os colonizadores respondiam com armas de canhões.

Como bem lembra Lidiane Alves do Nascimento e Marilúcia Mendes Ramos, no artigo intitulado "A memória dos velhos e a valorização da tradição na literatura africana: algumas leituras", publicado em 2013:

As narrativas orais, ouvidas dos velhos, não podem ser percebidas como invenções particulares, uma vez que mesmo se configurando como histórias pessoais, são influenciadas, indubitavelmente, pela voz narradora, seu meio de interação, suas ordens morais, sociais e outros aspectos que tais (NASCIMENTO. RAMOS, 2013, p.01).

Logo, essa narrativa apresenta valores que ultrapassam os limites subjetivos do narrador. Apresenta, outrossim, aspectos da identidade de um povo que busca a emancipação cultural, ainda que para isso tenha que fazer uso da língua do antigo dominador, mesclando a ela vocábulos próprios das línguas crioulas, tais como seculo, o conselheiro do líder da aldeia; kota, o mais idoso da comunidade; cubata, casebre; jango, uma espécie de caramanchão coberto de capim onde as pessoas se reúnem para discutir assuntos da comunidade; soba, o chefe da tribo; entre outros.

Dessa forma, o texto Kalimba, de Maria Celestina Fernandes, faz jus ao recurso da memória que, ao trazer à luz os traços do passado, resgata a esperança em uma utopia que pressupõe a retomada das terras e a valorização da herança cultural.

Outro ponto interessante a ser notado é a figura do velho nas literaturas africanas. Em geral, ele é sempre apresentado como o guardia $\square$ o da memória e da tradição. Em Kalimba dois merecem destaques: a avó de Kababo, N’Hakababu, e o velho camponês. A avó foi a primeira a atender ao apelo do neto e a desfrutar das maravilhas proporcionadas pelo pássaro:

transformações que têm passado as narrativas orais, afirma que, na modernidade, a contação de história também se torna uma arma contra o colonialismo. Por isso, nesse tipo de texto tem sido substituída a fórmula utilizada por Celestina pela "o que vai ser narrado aconteceu em algum lugar, mas poderia acontecer aqui, hoje ou amanhã" (FANON, 2010, p. 275), imprimindo ao fato narrado uma perspectiva mais ambígua. 
Ora, aproveitando a ausência dos avós, Kababo entrou em casa e foi pedindo ao pássaro as coisas boas $[\ldots]$

Depois de tudo pronto, o neto foi chamar a avó, que estava no grupo das mulheres.

- Vovó N’Hakababu, vovó N’Hakababu! Vem só ainda.

- Xé, rapaz, toma juízo, o que você quer?

- Vem, me ouve só, faz favor.

Dada a súplica insistente, as outras mulheres aconselharam-na a ir ouvir o que o maroto tinha para dizer. [...]

E qual não foi o espanto! Ao ver tanta fartura, a idosa começou a tremer e só passados muitos segundos conseguiu arranjar fôlego para exclamar.

- Haka! Haka! Meu neto, onde é que encontraste isto tudo?

- Come só, vovó, não fala nada - respondeu (FERNANDES, 2015, p. 21).

O velho camponês é aquele que oferece o pássaro kalimba aos rapazes que estavam à procura de comida para seu povo:

Entretanto, no momento em que o em que o moço recebia o pássaro, o homem [velho camponês] falou:

- Olha, fizeste muito bem, este pássaro tem poderes mágicos. Sempre que tiveres alguma necessidade, basta pedir: "Kalimba, quero água, quero comida ou qualquer outra coisa", e tudo aparecerá no mesmo instante, até a seca da vossa terra terá fim (FERNANDES, 2015, p. 14).

Como se vê, a figura do idoso é apresentada como perseverante: a avó que atende ao chamado do neto, diferente do avô que se recusa. A avó é o símbolo da sabedoria e da generosidade. O velho camponês é o portador da sabedoria.

Diante da oferta do kota, Kababo aceita, pois sabe que este tem sabedoria e, por isso, sabe muito bem o que faz, não seria capaz de enganá-lo. Este velho é aquele que transfere sua riqueza ao mais jovem, à futura geração, transfere seu bastão na figura do pássaro que, em algumas culturas africanas, segundo o Dicionário de Símbolos, representa o "espírito absoluto e do conhecimento puro [...] a força vital" (BECKER, 1999, p. 210). Kababo confia, garante o sustento de todos da tribo e torna-se o soba de todos, torna-se o líder de sua aldeia.

Desse modo, a figura do velho é apresentada como aquele que conserva o passado, interligando-o ao presente. É aquele que transfere a tradição dos seus conhecimentos aos pósteros e $a \square$ contribuição que esta significa na formação identita $\square$ ria de uma nova geração.

Kababo é o símbolo da persistência e da fidelidade que deve ter o jovem nacional. Sua confiança estava calcada nos valores da tradição traspassada pelo tempo e pela história. Ele só se tornou o chefe de todos porque respeitou a tradição e, por isso, foi premiado com a "bengala de soba". Em Kalimba, a cultura nacional popular é preservada pela sabedoria e confiança estabelecida entre o kota (velho) e o jovem Kababo.

Este contraponto velho versus jovem, sabedoria versus imprudência aparece também no conto $A$ borboleta cor de ouro. Neste conto, o enredo apresenta a história da borboleta dourada que resplandecia todos os lugares por onde passava, "Até mesmo as 
noites mais escuras se tornavam claras quando ela as surpreendia" (FERNANDES, 1990, p. 27).

Certo dia, vendo uma paisagem em que as culturas se mostravam muito pobres, resolve pousar no topo de um imbondeiro, de modo a deixá-la reluzente como ouro. $\mathrm{O}$ propósito da borboleta, segundo ela mesma "fala" na narrativa, era alegrar aquele povo sofrido e fazê-los distrair um pouco de suas preocupações.

Levando a cabo as estratégias analíticas utilizadas anteriormente, é possível encontrar diversas imagens metafóricas também em $A$ borboleta cor de ouro. Em primeiro lugar, vale analisar a figura da borboleta presente já no título do conto. Conforme o Dicionário de Símbolos, ela representa a alma, mas também a vaidade e a futilidade e, também, é símbolo da ressurreição e da imortalidade. Ou seja, visto que a borboleta pousa sobre a árvore com o propósito de alegrar aquele povo sofrido, ela age no conto como a alegria que está no interior de cada pessoa e que, ainda que os sofrimentos insistissem em destruir a vida, esta se manifesta como a alma incessante por vida e por dar a vida, como a alegria que sobrevive dentro de cada ser humano. Argumento que pode ser sustentado, visto que o ouro é considerado o elemento mais nobre entre os metais, ou seja, a alegria é o que o ser humano tem de mais nobre e que nas literaturas africanas faz questão de salientar. Desse modo, demonstra o quanto a força deste povo sobrevive a qualquer situação de conflito, miséria e exploração.

As figuras do velho e do jovem aparecem nesta narrativa de modo bastante díspares:

Certo dia, a borboleta cor de ouro, ao passar por uma sanzala resolveu poisar no topo de um imbondeiro repleto de múcuas.

Mal a borboleta poisou na árvore as múcuas e a própria árvore ficaram tão amarelas e reluzentes que parecia mesmo ouro.

Um velho que passava na altura, ao deparar com aquele inacreditável espectáculo, correu a chamar por toda a vizinhança.

- Manos, venham, venham ver, caíu ouro na nossa sanzala. Olhem só como o imbondeiro está coberto de ouro. Estamos ricos. (FERNANDES, 1990, P. 27)

O velho, como aquele que possui a sabedoria, é também aquele que é capaz de reconhecer a essência das coisas, dos elementos. Mas não apenas reconhece, ele compartilha com os outros aquilo que realmente deve ser vivido, aquilo que, de fato, deve ser valorizado, por isso chama toda a vizinhança para participarem daquela alegria que estava vivenciando.

O jovem, em contrapartida, ao ver o belo, quer guardá-lo para si:

Enquanto decorria aquela animação [ao testemunharem aquela maravilha produzida pela borboleta], alguém de entre a multidão, por sinal o mais jovem rapazito do grupo, pôs-se a magicar na maneira de se tornar rico possuindo a borboleta, a fonte do ouro.

- Se eu conseguir apanhar esta borboleta poderei transformar tudo em ouro e adeus pobreza, serei eu o único homem rico cá do sítio. (FERNANDES, 1990, p. 28) 
Por falta de conhecimento e maturidade, o jovem não é capaz de perceber que toda a alegria só tem sentido se ela for vivida em comunhão com as outras pessoas. É no exercício da alteridade que se apoia todo o relacionamento humano. Ao tentar prender, guardar para si aquela borboleta, o jovem é exposto às consequências da vida e de suas escolhas.

Diferente do que fizera Kababo em Kalimba, que dividiu tudo o que a ave podia oferecer com os membros da comunidade, em $A$ borboleta cor de ouro, o jovem, assim como a maioria dos jovens em Kalimba, não segue o exemplo dos mais velhos, está em uma situação de aprendizagem, porém, nem sempre é possível uma segunda chance em suas escolhas.

Em Kalimba, os jovens ignoraram a oferta do velho sábio, mas houve aquele que deu ouvidos e, assim, todos puderam ter uma segunda chance usufruindo dos benefícios que Kababo os proporcionaram. Em $A$ borboleta..., porém, o jovem garoto engana e prende a borboleta, mas as consequências dessa captura o marcam para toda a vida:

Rapidamente o rapaz ambicioso encontrou uma ideia e sem dizer nada a ninguém começou a pô-la em prática. [...] A borboleta que era muito amável e adorava estar entre as pessoas nem sequer lhe passou pela cabeça as más intenções do rapazito e logo foi descendo sempre cantando e dançando. [...] Tão distraídos se encontravam que ninguém reparou na armadilha que estava preparadinha para apanhar a borboleta e, no preciso momento em que ela poisou no terreno, zás, o rapaz lançou a rede e aprisionou-a. (FERNANDES, 1990, p. 29-39)

O jovem, deste modo atrai para si e a cegueira pela ausência do sol, visto que este o padrinho de tal borboleta, o Rei Sol, símbolo da razão e da coerência:

A voz do Rei Sol soou por toda a sanzala.

- Eu sou o Rei Sol. Dou vida e calor por onde quer que passe. A minha afilhada, a princesinha borboleta recebeu de mim o dom de alegrar e iluminar os corações dos mais necessitados. Tu, jovem ambicioso, pela tua ganância quiseste destruir a minha tarefa. Recairá sobre ti a maldição.

Daqui por diante nunca mais terás a felicidade de ver a luz que irradio. Cego ficarás para todo o sempre. (FERNANDES, 1990, p. 32)

E o conto termina com a moral que diz que "a maldição desmedida leva muitas vezes à desgraça” (FERNANDES, 1990, p. 33).

Ou seja, a imprudência juvenil, unida a audácia de querer interferir na natureza, foi capaz de trazer para a vida a angústia da perda. Deste modo, depreende-se que, o homem que desafia a natureza está fadado a ser castigado, já que a natureza é a mãe de todos, e dela depende a vida de todos na terra.

\section{ALGUMAS CONSIDERAÇÕES:}

Enfim, com as narrativas de Kalimba (2015) e A borboleta cor de ouro (1990), Maria Celestina Fernandes traz à tona um dos principais valores perpetuados por sua cultura 
de África: a sabedoria é a marca daqueles que muito lutaram e contribuíram para a formação da nação angolana. Assim como afirma Fanon, Fernandes atualiza os conflitos da sociedade, moderniza as formas de luta e os tipos de armas (FANON, 2010, p. 275). Em sua narrativa de Kalimba, Kababo não teria se tornado o kota de seu povo se, assim como os outros jovens, tivesse ignorado a proposta do velho camponês e, além disso, se tivesse ignorado as suas recomendações de não dizer nada a ninguém até que o tempo fosse propício.

Em $A$ borboleta cor de ouro, porém, o destino do jovem não é feliz, pois ele não foi capaz de viver a alegria da admiração, como fizera o velho. Ao contrário de Kababo que divide o que possuiu, o jovem rapazito quis guardar apenas para si as riquezas que poderiam vir da prisão da borboleta que transformava tudo o que tocava em ouro.

Deste modo, reconhecer os mais velhos é, de fato, valorizar a história de seu povo, é não deixar suas origens se esvair. Benjamin Abdala Junior, ao discutir sobre a arte engajada, afirma que

A práxis histórica de um grupo social desenvolve modelos de trabalho que podem passar para o conjunto da cultura nacional. Nesse sentido, esses esquemas podem ter sua origem descaracterizada, quando são apropriados pela ideologia dominante (ABDALA JR., p.85, 2007).

Nesses termos, a voz feminina de Maria Celestina Fernandes recuperas em suas narrativas infantis, um modelo cultural que já faz parte de sua nação e que, ainda que tenha sofrido diversas intervenções da ideologia dominante, continua viva no imaginário simbólico popular, como marcas de resistência e de luta.

Em Kalimba e em $A$ borboleta cor de ouro, a memória coletiva serve ao leitor em formação (a criança) como instrumento de libertação, na medida em que se reconhece uma cultura dominante que se aproxima e se faz superior, mas que não é forte o suficiente para aniquilar o saber popular e, portanto, a cultura nacional. Sendo assim, nessas narrativas curtas e com linguagem destinada aos pequenos, Maria Celestina Fernandes deixa clara a sua vontade de revelar aos leitores as múltiplas faces da cultura nacional angolana, fazendo do seu fazer literário um lugar de resistência diante de seu passado recente de descolonização e das novas colonizações simbólicas advindas das culturas de massa.

\section{REFERÊNCIAS:}

ABDALA JR., Benjamin. Literatura, História e Política: Literaturas de Lingua Portuguesa no Século XX. 2. ed. São Paulo: Ateliê Editorial, 2007.

BECKER, Udo. Dicionário de Símbolos. São Paulo: Paulus, 1999.

CHAVES, Rita. A formação do romance angolano. Coleção Via Atlântica, número 1. São Paulo: Via Atlântica, 1999. 
FANON, Frantz. Os condenados da terra. MG: Editora UFJF, 2010.

FERNANDES, Maria Celestina. A borboleta cor de ouro. Luanda: União do Escritores Angolanos, 1990. . Kalimba. São Paulo: Editora Kapulana, 2015.

FILHO, José Nicolau Gregorin. Literatura Infantil: Múltiplas linguagens na formação de leitores. SP: Melhoramentos, 2012.

LE GOFF, Jacques. A Civilização do Ocidente Medieval. SP: EDUSC, 2005. . História e Memória. 5. ed. SP: Editora da Unicamp, 2003. . "Memória", "Passado presente" e "Idades Míticas". In: Enciclopédia Einaudi - 1. Memória - História. $5^{a}$ ed. Campinas: Editora da Unicamp, 2008.

NASCIMENTO, Lidiane Alves do. RAMOS, Marilúcia Mendes. "A memória dos velhos e a valorização da tradição na literatura africana: algumas leituras". In: $A$ cor da cultura. Ano 2013.2 Disponível em: <http://www.acordacultura.org.br/artigos/01112013/a-memoria-dos-velhos-e-avalorizacao-da-tradicao-na-literatura-africana-algumas-leituras>. Acesso em: abril/2016.

TRESIDDER, Jack. The Watkins Dictionary of Symbols. London: Watkins Publishing, 2008. 